\title{
Diálogos interamericanos: literaturas migrantes e memória em Abla Farhoud e Salim Miguel
}

\author{
Inter-american dialogues: migrant literatures \\ and memory in Abla Farhoud's and Salim Miguel's works
}

Luciana Wrege Rassier

Universidade Federal de Santa Catarina - Santa Catarina - Brasil

$\diamond$

\begin{abstract}
Resumo: No presente artigo, analiso os romances Nur na escuridão (1999) do líbano-brasileiro Salim Miguel e Le bonheur a la queue glissante (1998) da líbano-quebequense Abla Farhoud, que relatam a história de migração do Líbano para o Brasil e do Líbano para o Canadá. Ambos protagonistas, o pai culto e a mãe analfabeta, sublinham o caráter lacunar de suas memórias e a experiência radical da alteridade em contexto migratório, que implica um retorno constante a si mesmo.
\end{abstract}

Palavras-chave: Literatura comparada; Literaturas migrantes; Memória; Abla Farhoud; Salim Miguel.

\begin{abstract}
In this article I study the novels Nur na escuridão (1999) by the Lebanon-Brazilian Salim Miguel and Le bonheur a la queue glissante (1998) by the Lebanon-Canadian Abla Farhoud, which tell the migration from Lebanon to Brazil and from Lebanon to Canada. Both main characters undeline the blanks in their memories and the radical experience of alterity in a migratory contexto, which implies a ceaselessly return to oneself.
\end{abstract}

Keywords: Compared literature; Migrant literatures; Memory; Abla Farhoud; Salim Miguel.

Em "Pensando a literatura comparada como campo de singularidade e inovação", Rita Terezinha Schmidt articula reflexões recentes de Martha Nussbaum, Gayatri Spivak e Tzvetan Todorov sobre o papel fundamental que as Ciências Humanas em geral e a Literatura de modo mais específico têm na manutenção da democracia, apesar de serem relegadas a um lugar marginal por políticas públicas educacionais submissas a um modelo mercantilista hegemônico implantado nas universidades:

O movimento em direção ao outro, a visão dialógica das culturas, tanto do ponto de vista transnacional quanto intranacional, e a atenção à diversidade de línguas e linguagens marcam a história do comparatismo como uma área do saber e sua dimensão politicizada, inscrevendo-o num sistema de valores e trocas na contramão dos fluxos do capital e de sua projeção de um mundo único e aberto à competitividade e consumo, uma imagem falaciosamente integrativa [...] (SCHIMIDT, 2013, p. 307).

Assim, por sua ligação intrínseca com a diversidade, a literatura comparada tende a insurgir-se contra a tendência homogeneizante presente tanto no monopólio linguístico como na subordinação e na instrumentalização das margens e do outro. Propiciando um descentramento, ela associa diferentes formas de conhecimento e de compreensão:

O reconhecimento da heterogeneidade cultural e a relativização dos discursos e valores como efeito da inscrição do literário na ordem histórico-cultural e geopolítica planetárias, concomitantemente aos trânsitos interdisciplinares, pela aproximação do discurso da crítica literária com os discursos das Ciências Humanas e das Artes, reconfigurou a disciplina acadêmica a tal ponto que o comparatismo, acima e além de quaisquer definições, assume a forma singular de uma hermenêutica pluritópica [...] (BITTENCOURT e SCHMIDT, 2013, p. 09).

Movendo-se entre disciplinas e culturas, o comparatista aproxima-se do "migrante epistemológico" (GARCÍA CANCLINI, 1999, p. 215), munido de instrumentos variados para pensar não apenas sobre os múltiplos trânsitos que compõem a cultura da mobilidade contemporânea mas também sobre "os termos e discursos que a enunciam" (GIN, 2011, p. 346). 
No âmbito das relações literárias interamericanas, Diane Brydon sublinha importância de um diálogo entre pesquisadores brasileiros e canadenses que vá além das fronteiras institucionais tradicionais (2001, p. 81) e salienta a capacidade que têm as narrativas literárias de questionar noções tradicionais de território ou de literatura nacional ao apresentar modos de relacionamento complexos ligados aos movimentos contemporâneos das culturas em trânsito (2001, p.68). É precisamente esse componente relacional que Patrick Imbert, em sua reflexão sobre cultura e deslocamento, identifica na origem dos discursos culturais diversos:

[Dès lors,] ce qui permet de produire des discours culturels divers n'est pas l'isolement, qui est de toute façon en bonne partie une fiction, mais le contact avec les autres groupes. C'est la relation, sinon l'interpénétration qui permet l'épanouissement et la multiplication de la diversité culturelle et non l'enfermement dans des positions défensives et des territoires aux frontières visant la permanence d'une pureté imaginaire (IMBERT, 2004, p. 66).

$\mathrm{Na}$ mesma perspectiva, Zilá Bernd enfatiza o enriquecedor aporte da heterogeneidade cultural das literaturas migrantes no contexto das Américas:

Concluímos que é, hoje, pelas literaturas migrantes, diaspóricas e em deriva (consideradas marginais) que a literatura das Américas experiencia o novo, adere plenamente a formas culturais híbridas e inaugura modos transnacionais de pensar suas produções estéticas que deixam de definir-se unicamente em termos dos espaços exíguos de suas identidades nacionais (BERND, 2010, p. 23-24).

Essa noção de migrância, desenvolvida por Pierre Ouellet em L'esprit migrateur, é inerente a um movimento do Um em direção ao Outro, movimento transgressivo na medida em que vai além das fronteiras da individualidade e dos laços originais. $(2005$, p. 19). Tal "estesia migrante" não se restringe às obras de autores oriundos da imigração, relacionando-se de modo mais amplo à mobilidade intersubjetiva e intercultural. É nesse sentido que Rita Godet, no verbete "Errância/ migrância/migração", do Dicionário das mobilidades culturais: percursos americanos, explicita a presença, na literatura migrante, de uma “'espécie de 'tradução' ou de 'translação' do eu em outro. O que está em jogo é o confronto com a alteridade entendido mais como um processo de migração contínua do que como um simples retorno a si mesmo" (GODET in BERND, 2010, p. 192). Aliás, o teórico quebequense expande ainda mais essa questão, sublinhando, em recente entrevista, tanto a migração imaginária da literatura quanto a experiência de alteridade, de mobilidade e de migrância inerentes à experiência estética:

Pierre Ouellet: [...] c'est pourquoi maintenant, on ne parle plus tellement d'auteurs migrants, on parle de littérature migrante, c'est la littérature elle-même qui est un processus de migration imaginaire, par l'esprit. Zilá Bernd: De n'importe quelle géographie.

Pierre Ouellet: Exactement. C'est pourquoi on dit au Québec que toute forme d'expérience artistique, esthétique, littéraire poétique est, d'une certaine manière, un contact avec l'autre ou avec l'ailleurs. C'est un processus qui nous mène à une forme d'altérité, donc, ça participe des grands phénomènes qu'on connaît aujourd'hui de mobilité, de migrance. (OUELLET, 2015, p. 232).

Portanto, embora essa experiência da mobilidade contemporânea não se limite à literatura migrante, também cabe analisar como ela pode ser ficcionalizada, a partir de perspectivas diversas, através de personagens em contexto de migração:

Cross-cultural movements may take place in the form of migrant literature, either through the migrant that look inwardly at the new culture, the one that looks outwardly to the place of a so-called origin or the one that is caught in between, in transit between worlds, spaces, memories and experiences. (ALMEIDA, 2011, p. 255)

Além disso, ao relatar sua experiência de migração, certos autores problematizam "a representação do sujeito na escrita, nela inscrevendo a voz de estrangeiros, de exilados, ou seja, de pessoas que se percebem como Outro no país de acolhida" (PATERSON, 2015, p. 181).

É a partir desses pressuspostos que me interesso no presente artigo pelos romances Nur na escuridão (1999) do líbano-brasileiro Salim Miguel e Le bonheur a la queue glissante (1998) da líbano-quebequense Abla Farhoud.

\section{Le bonheur a la queue glissante, memórias de uma matriarca analfabeta}

Nascida no Líbano em 1945, Abla Farhoud chega com seus pais ao Canadá em 1951, retornando a seu país natal entre 1965 e 1969, antes de se instalar em Paris, onde estuda teatro e atua como atriz. De volta ao Quebec em 1973, publica, no início da década de 1980, a primeira de suas peças. Tanto por seus textos de dramaturgia quanto por seus romances, recebeu prestigiosos prêmios (Prix Arletty 1993: Les Filles du 5-10-15 ; Prix FranceQuébec 1999: Le bonheur a la queue glissante; Prix du roman francophone 2006: Le fou d'Omar). Dentre os escritores árabo-quebequenses/canadenses, é a única que 
utiliza cinco registros de língua: o joual (linguajar popular quebequense), o francês padrão, o francês coloquial, inglês, o árabe falado coloquialmente no Líbano e o árabe clássico (DAHAB, 2011, p.99). Considerada um dos expoentes da literatura quebequense contemporânea, notadamente no que tange à literatura migrante, sua obra ficcional tem fortes traços autobiográficos, os quais ganham o primeiro plano em seu romance mais recente, Toutes celles que j'étais (2015) - sobre o qual a autora afirma que os filhos de migrantes levam a vida toda tentando encontrar um lugar de apaziguamento entre o desenraizamento e o mito do retorno idílico (SAINTJACQUES, 2015).

Le bonheur a la queue glissante corresponde ao relato em primeira pessoa da matriarca Dounia, que, aos 75 anos, relembra fatos de sua infância e juventude, idade adulta e velhice. Sua vida é marcada pela migração: ele emigra com seu marido Salim e seus filhos (Abdallah, Farid, Samir, Samira e Myriam) para o Quebec (onde nasce a caçula, Kaobab); após quinze anos, retornam ao Líbano, mas devido à guerra civil voltam ao Canadá, instalando-se em Montreal. No capítulo Inaugural, a matriarca diz aos filhos que a coloquem em um asilo quando ela não mais puder cuidar de si mesma. Apesar de todos protestarem com veemência, é exatamente o que acontece, depois que Dounia fica viúva e dependente.

O texto da contracapa da edição de bolso propõe um pacto de leitura que privilegia a cultura oral libanesa, veiculada pela migrante analfabeta:

Dounia, 75 ans, ne sait ni lire ni écrire et ne parle que l'arabe. Elle laisse la parole à Salim, son mari, et à ses enfants, qui parlent une langue qui lui est étrangère. Elle se croit muette, ininteligente. Dans le bonheur a la queue glissante, ele murmure avec naïveté et sagesse une culture orale surprenante qui glisse em nous comme le bonheur. Avec ele, on se laisse bercer par les proverbes libanais, on questionne la vie et la mort, on rit et on pleure.

O fato de viver anos em um país cuja língua ela desconhece, relega Dounia à esfera familiar ("Je ne pouvais parler à personne. Je ne connaissais pas la langue du pays, je ne sortais jamais de la maison, je n'avais ni parents ni amies", FARHOUD, 2010, p. 32), na qual seu marido um conversador inveterado, que transforma o menor fato em um conto das Mil e uma noites (FARHOUD, 2010, p.41) - monopoliza a palavra, e na qual o idioma árabe dá lugar ao francês, na medida em que a maioria de seus filhos, com o passar do tempo, vai esquecendo a língua materna. A opressão que sofre por parte de Salim a leva à incapacidade de se exprimir:

Quelquefois j'aimerais pouvoir parler, avec des mots. J'ai oublié, avec le temps. Depuis une dizaine d'années, il m'arrive d'essayer. Ça sort de ma bouche en boules déjà défaites. J'oublie des bouts de mots en dedans et personne ne comprend. Même moi, je trouve que tout est mêlé. Je vois bien que ce qui est dans ma tête et ce qui sort de ma bouche n'ont rien à voir. Alors je me tais (FARHOUD, 2010, p. 16).

Tal silêncio corresponde a um exílio interior que vem se acrescentar a dois outros: a mudança de seu vilarejo para o do marido, após o casamento, e a posterior imigração do Líbano para o Canadá. Dounia vive para a família, passa seus dias a cuidar da casa e do marido, a cozinhar pratos típicos, para ele, seus filhos e netos. É graças à insistência de sua filha Myriam, a qual é escritora, que a matriarca rompe seu ensimesmamento e seu silêncio e toma a palavra para relatar a história da família:

Myriam s'était arrêtée d'écrire et me regardait. On aurait dit qu'elle cherchait quelque chose à l'intérieur de moi. Elle m'a dit: 'J'aimerais écrire un livre sur toi, mère". J'ai ri. J'ai peut-être rougi.

"Pourquoi moi? Es-tu en mal d'histoires?... Demande à ton père, il en connaît beaucoup".

- J'ai écrit une quinzaine de livres et je n'ai jamais parlé de toi. J'ai le goût de te connaître.

- Drôle de façon de me connâitre!

- Est-ce que tu veux?

- Même si je disais non, qu'est-ce que ça changerait? (FARHOUD, 2010, p. 30).

Embora Myriam demonstre interesse por sua mãe, fazendo com que se sinta valorizada, Dounia sublinha que se considera ao mesmo tempo próxima e distante dessa filha, que passou maior parte de sua vida no Canadá ("Je ne la comprends pas toujours très bien. Elle non plus, peut-être. Nous avons toutes les deux la même langue maternelle, mais que d'années elle a passées à étudier une autre langue. Myriam a vécu presque toute sa vie ici" - FARHOUD, 2010, p. 25). Essa distância, marcada pela inscrição do indivíduo em um idioma e uma cultura, é intensificada pelo fato de a filha haver estudado, ao passo que a mãe permaneceu analfabeta mesmo em sua língua materna ("Je ne sais pas si c'est seulement la langue ou simplement qu'elle est d'une autre génération ou peut-être l'école. Ça change beaucoup une personne d'avoir étudié longtemps" - FARHOUD, 2010, p.26). Aliás, Dounia tece um comentário semelhante em relação a sua outra filha: "Kaobab est professeure de langues, moi, je parle à peine ma propre langue et quelques mots de français et d'anglais" - FARHOUD, 2010, p. 14). A matriarca lastima o fato de não saber ler e escrever, de não haver estudado (FARHOUD, 2010, p.31), e sublinha o contraste de sua situação não só em relação a seus filhos, mas também em relação a seu pai - que era o padre do vilarejo no Líbano, um assíduo leitor de jornais, um homem culto que falava 
aos filhos sobre califas, sultões e profetas ("Mon père nous parlait souvent d'Ibn Arabi, d'Omar al Khattab, du sultan El Rachid, du profete Mouhammad, de Jésus, et de sa Mère et de Marie-Madeleine, et de bien d'autres encore - FARHOUD, 2010, p. 80).

Por sua vez, na conversa com seus filhos, Dounia utiliza-se frequentemente de ditados em árabe. Por um lado, trata-se da transmissão de um importante elemento cultural, tendo em vista que essas frases feitas são portadoras da sabedoria popular. mas, por outro lado, Dounia as utiliza no âmbito de uma estratégia bastante específica, evitando falar e refletir sobre seu passado : "Je réponds par um dicton um proverbe ou une phrase toute faite quand mes enfants me posent une question sur mon passé, c'est plus facile que d'avoir à chercher la vérité, à la dire, à la revivre..." (FARHOUD, 2010, p. 31).

Myriam demonstra um interesse particular por tais ditados, anotando-os sistematicamente. No romance, eles ocupam um lugar privilegiado. Eles são integrados à narrativa em língua francesa, podendo passar despercebidos para o leitor que não seja familiarizado com tal cultura, já que não são destacados nem por caracteres itálicos nem pelo uso de aspas. Ao final do livro - em uma seção cujo título, Lexique, não indica claramente do que se trata - os mais de cinquenta ditados são agrupados na ordem em que aparecem no romance, grafados em árabe e seguidos da tradução em língua francesa (FARHOUD, 2010, p. 153-159). Percebe-se então que o próprio título do romance ("Le bonheur a la queue glissante") é um ditado, utilizado por Dounia para se referir ao caráter efêmero de seus momentos de felicidade (FARHOUD, 2010, p.45).

Inicialmente, a matriarca aceita a proposta de Myriam e vai com frequência à casa da filha, a fim de lhe contar suas lembranças. Mas a insistência e a quantidade de perguntas feitas acabam originando um conflito entre elas, sobretudo quando se trata de falar de assuntos muito sensíveis para Dounia, como a violência de seu pai, de seu marido ou o distúrbio psicológico de seu filho primogênito, Abdallah. A obstinação de Myriam faz com que sua mãe interrompa seu relato, alegando estar doente e afirmando que tudo o que contara até então era mentira (FARHOUD, 2010, p. 122).

$\mathrm{O}$ fato de a narrativa ser feita na primeira pessoa do singular mascara, de certo modo, a intermediação da filha, dando ao leitor a sensação de ter acesso direto ao relato de Dounia. Mas o que se lê é o relato de Myriam, escrito em língua francesa a partir das conversas que tem, em árabe, com sua mãe. Ao longo do romance, há indicações tanto das lacunas de Myriam no domínio da língua árabe - ou seja, de possíveis falhas na compreensão do discurso materno - quanto da tendência que teria a manipular esse relato oral, imprimindo seu próprio recorte e interpretação dos fatos no texto que escreve:
[...] j'ai l'impression quelquefois d'être em présence d'une étrangère: sa façon d'hésiter, de chercher ses mots quando ele parle l'arabe, d'y mettre des mots de français et surtout sa manière de penser qui ne ressemble pas à la mienne (FARHOUD, 2010, p. 26)

- Tu es fatiguée, mère, repose-toi. Si tu ne veux pas parler d'Abdallah, il y aura um trou, c'est tout. Je le remplirai par autre chose. [...] (FARHOUD, 2010, p. 122).

Parfois, elle [Myriam] voulait que je pense comme ele, que je lui disse ce qu'elle voulait entendre. Elle me mettait les mots dans la bouche. Ce que je ne comprends pas, c'est qu'elle voulait connaître ma vérité [...], et en même temps on aurait dit qu'elle voulait la déguiser, la changer, la rendre plus extraordinaire (FARHOUD, 2010, p. 113).

"Est-ce que tu écris ce livre pour camoufler les choses, les ensevelir sous le tapis comme je l'ai fait toute ma vie ou pour montrer le vrai visage de ta mère? [...]" (FARHOUD, 2010, p. 114).

As citações precedentes revelam que Dounia analisa sua relação com Myriam, marcada pela diferença cultural no modo como veem o mundo, e a manipulação de seu relato pela filha escritora. O convívio entre as duas tem consequências significativas para a matriarca, que modifica sua rotina e sua maneira de ser. Dounia deixa de assistir à televisão para consagrar seu tempo a pensar naquilo que contará à filha e começa a pensar sobre sua vida. O exercício da memória faz com que Dounia veja sua vida e o mundo de modo mais reflexivo e crítico, graças à instigação de Myriam ("Une araignée qui tisse sa toile ne la voit pas, mais l'araignée n'a peut-être pas de fille pour lui poser des questions et la faire réfléchir sur sa vie, sur la vie") - (FARHOUD, 2010, p. 126). A matriarca "cava no vazio da memória" para "juntar os pedaços de seu passado", e acaba refletindo também sobre o próprio funcionamento da memória, sobre por que lembra de certos fatos mas não de outros (FARHOUD, 2010, p. 108, 113, 120):

Je creuse et je creuse ce qui me reste dans le creux de ma mémoire, espérant trouver um jour la paix dans cette tête pleine de trous et de crevasses. (FARHOUD, 2010, p. 108).

Je ne me souviens pas em détail de toutes les histoires, mais j'en ai retenu des bribes qui sont entrées dans ma tête sans que je me force [...]. Pourquoi est-ce celle-ci qui me revient à la mémoire et pas une autre? Si la vie demeure une énigme pour moi, la mémoire, c'est l'énigme de l'énigme... (FARHOUD, 2010, p. 80 grifo meu). 
Conforme aponta Patrick Imbert, dentre imprecisões nas lembranças de Dounia, ela chega a se interrogar se a autoridade religiosa a que recorreu certa vez seria o rabino, ou o padre, ou o iman, o que reflete um grande desapego às ortodoxias (2014, p. 210). Esse desenraizamento cultural ligado à dupla emigração da família ao Canadá se refere também ao apego ao Líbano. Ao associar seu lugar de pertencimento aos laços afetivos com seus filhos e netos, Dounia demarca-se de outros migrantes que cultivam o desejo de retornar ao país natal:

Certains immigrants disent: 'Je voudrais mourir là où je suis né.' Moi, non. Mon pays, ce n'est pas le pays de mes ancêtres, ni même le village de mon enfance, mon pays, c'est là où mes enfants sont heureux. [...] Mon pays, c'est mes enfants et mes petitsenfants, c'est moi, aujourd'hui, [...] Mon pays, c'est mes petits-enfants qui s'accrochent à mon cou, qui m'appellent sitto Dounia... dans ma langue. Je veux mourir là où mes enfants et mes petits-enfants vivent" (FARHOUD, 1998, p. 23).

O epílogo do romance mostra Dounia em um asilo, onde recebe raras visitas de seus filhos e netos, exilada em sua velhice, à beira da morte.

\section{Nur na escuridão, memórias de um patriarca esclarecido}

Desde sua estreia na literatura na década de 1940, Salim Miguel (Líbano, 1924) vem construindo uma obra extensa e variada, que conta com mais de trinta livros, entre romances, contos e crítica literária. Escritor, jornalista, roteirista, editor e gestor cultural, seu percurso ímpar no contexto cultural brasileiro valeu-lhe prestigiosos prêmios e distinções, como o Prêmio Machado de Assis, da Academia Brasileira de Letras, pelo conjunto de sua obra (2009); o prêmio Juca Pato de Intelectual do Ano (2002) da União Brasileira de Escritores (UBE-RJ) e o título de Doutor honoris causa da Universidade Federal de Santa Catarina (2002) ${ }^{1}$.

Chegou ao Brasil com os pais libaneses aos três anos de idade e, após curta temporada no estado do Rio de Janeiro, a família instalou-se no estado de Santa Catarina, em zona de colonização alemã. Tendo o árabe como língua materna, Salim Miguel foi alfabetizado em alemão, aprendendo português posteriormente, ao ingressar na escola. Dentre os escritores brasileiros de origem libanesa mais consagrados (Raduan Nassar,

\footnotetext{
Para maiores informações, ver o dossiê temático publicado pela revista Litteris em 2011, que comemorou os 60 anos da publicação do primeiro livro do autor (Rassier, 2011a), que reúne artigos acadêmicos, depoimentos, entrevistas, cronologia, bibliografia e traduções de trechos da obra de Salim Miguel.
}

Milton Hatoum e Alberto Moussa), é o único a ter passado os primeiros anos da infância no Líbano e também o único cuja obra aborda não só a instalação e a vida da família de migrantes no Brasil, mas também trata em detalhe da vida pregressa no Líbano e da viagem até o continente americano, conforme pontuei em estudo anterior sobre o romance Nur na escuridão:

[...] il vient combler une lacune de la littérature brésilienne concernant les récits de l'immigration libanaise, car il est pionnier quant à la narration assez détaillée de la vie au Liban, de la préparation et du déroulement du voyage jusqu'au Brésil, des différentes étapes d'adaptation des nouveaux arrivants, ainsi que du réseau d'entraide constitué par la communauté libanaise déjà en place (RASSIER, 2010, p. 191-192).

Essa narrativa, publicada pela primeira vez em 1999, recebeu os prêmios de melhor romance da Associação Paulista de Críticos de Arte (2000) e da IX Jornada de Literatura de Passo Fundo (2001, compartilhado com o escritor Antônio Torres por Meu querido canibal). Ela põe em cena a vida de Yussef e Tamina no Líbano; sua viagem, com três filhos, ao Brasil; a temporada no interior do estado do Rio de Janeiro, junto à irmã de Yussef; a instalação em comunidades de imigração alemã em Santa Catarina, e, posteriormente, em Florianópolis; o nascimento de outros filhos; a penosa evolução financeira do pai, de mascate a proprietário de armazém; as mortes na família, dentre as quais a da mãe e a do pai, sendo o falecimento deste o episódio que encerra o romance. Os fatos marcantes no Brasil e no mundo, assim como suas implicações na vida das personagens, constituem um pano de fundo que corresponde a um panorama do período compreendido entre as décadas de 1920 e 1980.

A trama adota a estratégia narrativa do relato de memórias, frequente na literatura contemporânea, notadamente no que tange aos escritos que colocam o migrante no primeiro plano (CURY, 2011, p. 04, 06). Se, por um lado, o patriarca se compraz em contar e recontar a estória da família aos filhos, por outro lado estes também o solicitam com frequência. Apesar de as lembranças do pai serem destacadas, os enfoques são múltiplos e a narração em terceira pessoa é uma simulação (APPEL, 2001, p. 101; MELLO, 2014, p. 177). Elementos autobiográficos são enfatizados pelo paratexto, lendo-se, respectivamente, no texto de orelha e na apresentação do autor:

Nur na escuridão conta a saga da família que veio do interior do Líbano e se estabeleceu em Santa Catarina. Salim Miguel, o filho mais velho de Youssef - e que tinha apenas três anos no desembarque tumultuado da Praça Mauá - comove o leitor neste romance autobiográfico. 
Nascido em Kfarssouroun, no Líbano, Salim Miguel era o menino de três anos que desembarcou em 1927 no porto do Rio, junto com os pais, duas irmãs mais novas e um tio. Depois de curta temporada em Magé (RJ), viveu dos cinco aos 19 anos em Biguaçu, vilazinha perto de Florianópolis [...]. Em 1943 a família fixou residência na capital catarinense, e foi ali que o primogênito [...] estreiou na literatura [...].

Já a narrativa ficcional fornece pistas mais sutis, pois embora o sobrenome da família coincida com o do autor (Miguel), raríssimas vezes o prenome Salim aparece, sendo a personagem identificada por expressões como "o filho mais velho" ou "o primogênito". Após a página de rosto, outro elemento paratextual que reforça o pacto autobiográfico é a seguinte precisão: "Os trechos da autobiografia Minha vida, de José Miguel, foram traduzidos do árabe por Alia Haddad" (MIGUEL, 2004, p. 07).

Também no romance, o patriarca Yussef-José escreve, em árabe, sua autobiografia em um caderno, a qual seria traduzida após seu falecimento, e da qual são transcritos sete trechos no penúltimo capítulo, relativos à morte de um dos filhos e à de sua esposa Tamina. Quatorze outros trechos da autobiografia são incluídos nos dezoito primeiros capítulos - sempre isolados por um traço horizontal, entre aspas e em fonte menor, precedidos ou seguidos de um breve comentário. Esse procedimento instaura um diálogo entre o relato intermediado pela instância narradora e o testemunho escrito deixado pelo patriarca. Mas as passagens do diário nem sempre exercem o apaziguador papel de um texto documental que viria a reforçar o que é contado pelo narrador, sublinhando não só a impossibilidade de se reconstituir certos fatos ("A anotação autobiográfica de Yussef pouco esclarece" MIGUEL, 2004, p. 58) mas também a primazia da versão várias vezes contada aos filhos:

Se bem que os dados não deixem qualquer resquício de dúvida, embora a versão do pai, em sua autobiografia Minha vida, seja a real, durante décadas outra versão foi inculcada na mente dos filhos. É a que acaba por prevalecer, mantém-se presente, ganha foros de verdade. Recusa ceder o lugar que lhe cabe na história e no seio da família (MIGUEL, 2004, p. 61).

Esse mecanismo contribui para instalar a dúvida e para sublinhar multiplicidade de pontos de vista em relação a um mesmo fato. Na mesma perspectiva, a fragmentação e complexidade da estrutura temporal reforçam a tendência a lacunas e imprecisões na reconstituição da estória familiar. Além de estarem presentes na própria construção da narrativa, essas lacunas e imprecisões são claramente evocadas em trechos relativos ao funcionamento da memória, dentre os quais a introdução ao capítulo 27, intitulado "Fios":

A memória se esgarça, flutua, se decompõe, se compacta. Fios se atam/desatam. Fragmentos somem e reaparecem. [...] Necessário preencher vazios que incomodam. Inútil o esforço consciente. A memória não possui uma lógica cartesiana. [...] Ela é acronológica. Pouco adianta teimar, nos esforçarmos na busca de recompor, pela ordem, o que se desgarrou, trazer de volta o que já foi, para que volte a ser. Idêntico ou modificado, nem importa. [...] Mesmo que acreditemos tê-lo conseguido, é inevitável que existam lapsos, ocorram falhas, incompreensíveis rupturas. É um complexo processo que foge ao controle e tudo parece comandar, disciplinar. Por vezes, o que nos chega nem é memória vivida, é memória de outrem que se nos incorpora reconstituída - e passa a ser nossa. Simulacros apenas? Quem sabe! (MIGUEL, 2004, p. 165-166).

O narrador explicita que essas rupturas e variações, inerentes ao funcionamento da memória, correspondem à maneira como o pai relata a saga familiar:

O pai titubeia, não se fixa, pula de um assunto para o outro, mais outro, outro ainda, sabe-não-sabe o que quer, de novo naquela técnica tão dele, que é a maneira própria do seu comunicar, adquirida nos tempos da infância, das lendas recolhidas de um fabuloso imaginário oral. De repente engrena. Retoma a explicação mais que conhecida, com variações na forma do narrar, na estrutura da frase, que para o pai, encharcado das histórias das Mil e uma noites, tem sempre um novo tempero, inédito sabor (MIGUEL, 2004, p. 24).

Esse imaginário oriental, de um pai que cultiva a leitura de obras literárias e históricas, também é transmitido aos filhos através das próprias estórias de as Mil e uma noites, de fábulas ("tradição milenar de sua gente"), de versos de poetas como Omar Khayam, de trechos dos Prolegômenos de Ibn Kaldun ou do Profeta de Gibran Kalil Gibran, ou ainda através de alusões ao esplendor da cultura árabe, ao período abássida, ao sultão Saladino, à biblioteca de Alexandria - notadamente no capítulo 26, significativamente intitulado "Orgulho" (MIGUEL, 2004, p. 160-164). Os dois capítulos que o precedem são igualmente consagrados à transmissão de elementos culturais, cultivada nos momentos em que Yussef, Tamina e seus filhos se reúnem no fim de semana, seja através do jogo de gamão (capítulo 25, Nard), seja através de pratos típicos, cuja enumeração corresponde à maioria das palavras em árabe, utilizadas na narrativa, marcadas no texto por caracteres itálicos (capítulo 24, Ritual). 
Cabe salientar o caráter híbrido do título bilíngue do romance, no qual a opacidade introduzida pela palavra Nur para o leitor que desconhece o árabe reflete o desconhecimento da família de libaneses em relação tanto à língua falada no país de acolhida quanto ao próprio país, seu povo e costumes. Nessa perspectiva, dois fatos merecem igualmente destaque. Em primeiro lugar, conforme é explicado ao leitor no capítulo inaugural, nur é a tradução em árabe da primeira palavra em língua portuguesa que Yussef compreende, ao desembarcar no Brasil, ao tentar mostrar ao motorista de táxi, na escuridão crescente do crepúsculo, o endereço ao qual deseja ir com a família:

O pai não entende o que o motorista quer dizer, em vão o homem repete mais alto, mais alto, luz. Luz. E faz uma careta, coça a cabeça, abre um sorriso que lhe revela os dentes perfeitos, puxa do bolso uma caixa de fósforos (a mãe murmura, tagur), tira um palito, acende, repete indicando a trêmula chama que logo se extingue, luz , rápido, acende outro palito, com ênfase repete o mesmo, letra por letra, 1,u,z, antes de mais um LUZ - e só aí o pai entende a palavra que jamais esqueceria e lhe abre as portas do novo mundo. Abana a cabeça. O motorista volta a sorrir: luz. O pai também: luz. Nur. (MIGUEL, 2004, p. 25).

Como fica evidenciada na passagem acima, a capacidade não só de traduzir de uma língua para outra, mas também de negociar estratégias de compreensão, de mover-se em direção ao outro, é apontada como uma chave para adentrar o "novo mundo". Em segundo lugar, tal fato se torna ainda mais significativo pelo próprio significado da palavra, nur, luz, e pela bela imagem da chama tênue e efêmera do palito de fósforo, metáfora da comunicação frágil e incipiente. A narrativa também trabalha com o aspecto formal da língua, ao decompor a palavra em letras isoladas ("letra por letra, 1,u,z") e ao grafá-la em letras maiúsculas para transcrever a ênfase dada pelo interlocutor ("antes de mais um LUZ").

Além desse trecho que, aliado ao título, constitui uma das chaves de interpretação do romance, a presença da língua estrangeira na narrativa restringe-se a alguns vocábulos esparsos, relativos sobretudo à gastronomia, não havendo a transcrição dos diálogos entre o pai e a mãe, nem dos das conversas que têm com os "patrícios" que os acolhem e auxiliam durante o período de instalação no Brasil. Embora durante toda sua vida Yussef declame poemas e cante em árabe, mesmo os filhos mais velhos, que se exprimiam nesse idioma quando pequenos, uma vez adultos pouco compreendem. Conforme demonstrei em estudo anterior (RASSIER, 2011b), essa perda da língua materna está na origem de "feridas identitárias" (MAALOUF, 1998) da segunda geração de migrantes, como vemos no trecho abaixo, em que o filho primogênito acompanha o pai já idoso, que visita antigos conhecidos no Rio de Janeiro:

\begin{abstract}
Por vezes sente-se alijado, um intruso, quando começam a conversar só em árabe. É que chegou um novo imigrante que nada conhece do português. De repente, para melhor se comunicar, necessitam do idioma original. Fica preso a um som, a todos os sons, que não lhe são alheios, procura captar o sentido de algumas palavras, mas o entendimento geral lhe foge, nunca consegue apreender as frases e o que significam, e se sabe que buka é choro, um choro que agora procura conter, segura o bolo na garganta, aquela iuhadditu lhe escapa por inteiro (MIGUEL, 2004, p. 22).
\end{abstract}

Se a segunda geração de migrantes se encontra no entre-dois cultural, deparando-se com lacunas e perdas de elementos identitários, o mesmo acontece com a primeira geração, como fica evidenciado no caso de Yussef que, já idoso, refuta a incitação dos filhos a retornar ao do país natal, argumentando que o Líbano atual não corresponde àquele que conhecera, décadas antes, e incitando seus filhos a irem em seu lugar:

Repele os convites, as provocações. Afirma: jamais me passou pela idéia retornar ao Líbano, por Allah, sinto saudades, sinto, mas agora nem a passeio; antes, quando Tamina vivia, quem sabe? Brinca: afinal, tenho minha carteira modelo 19, me dá direito legal de ficar no Brasil, ser brasileiro, por que querem me ver fora, hein, cansaram-se de mim? A seguir, sério: filhos e netos aqui, não demora filhos dos netos, Tamina, Samir e Fádua enterrados aqui, também aqui serei enterrado, ao lado deles, no mesmo chão (MIGUEL, 2004, p. 161).

Consciente que seu país de origem só existe em suas lembranças, o patriarca recria, pela memória reinventada, mesclada a seu imaginário, a suas leituras e conhecimentos de história, "um Líbano que nem existira como tal, era um fabuloso país retirado de livros, das histórias, de narrativas orais, [era] um Líbano de antes do Líbano" (MIGUEL, 2004, p. 163).

Os romances Nur na escuridão (1999) Le bonheur a la queue glissante (1998) colocam em cena o relato, à margem da historiografia, de migrantes libaneses. Tanto Yussef, o patriarca culto, quanto, a matriarca analfabeta, tentam transmitir a cultura do país de origem a seus filhos, em um constante movimento em direção ao Outro, que torna ainda mais salientes as questões identitárias relativas ao contexto de migração. A perda da língua materna, por parte dos filhos, cria um distanciamento entre as duas gerações, e reflete-se na própria narrativa, na qual os vocábulos em árabe são pouco frequentes, sendo destacados em itálicos ou, no romance de Abla Farhoud, 
impressos em caracteres arábicos mas agrupados em uma seção à parte. Pais e filhos, presos no entre-dois cultural, veem-se impelidos a constantemente retornarem a si mesmos e a moverem-se em direção ao outro. O retorno ao país de origem dá-se simbolicamente através da memória, cujas imprecisões, lacunas e incoerências são associadas às estratégias narrativas, indicando o texto literário como um lugar de memória.

\section{Referências}

ALMEIDA, Sandra Goulart. Transnational Mouvements, Cultural Mobility and Literary Transits. In: GIN, Pascal; MOSER, Walter (org.). Mobilités culturelles/Cultural mobilities. Ottawa: Presses de 1'Université d'Ottawa, 2011. p. 253-267.

APPEL, Carlos Jorge. Duas ou três coisas sobre o romance de Salim Miguel. In: CARDOZO, Flávio José (org.). Salim na claridade. Florianópolis: Fundação Catarinense de Cultura, 2001. p. 109-120.

BERND, Zilá (org.). Dicionário das mobilidades culturais: percursos americanos. Porto Alegre: Litteris editora, 2010.

BITTENCOURT, Rita Lenira e SCHMIDT, Rita Terezinha (org.). Fazeres indisciplinados - estudos de literatura comparada. Porto Alegre: Editora da UFRGS, 2013.

BRYDON, Diane. Global Designs, Postcolonial Critics: Rethinking Canada in Dialogue with Diaspora. Ilha do Desterro, Florianópolis, v. 40, p. 61-84, jan-jun. 2001.

CURY, Maria Zilda. Nur na escuridão: histórias da imigração. Litteris, Rio de Janeiro, n. 8, p. 1-15, set. 2011.

DAHAB, F. Elisabeth. Voices of Exile in Contemporary Canadian Francophone Literature. Plymouth: Lexington Books, 2011.

FARHOURD, Abla. Le bonheur a la queue glissante. Montréal: Éditons TYPO, 2010 (nouvelle édition).

GARCÍA CANCLINI, Néstor. La globalizatión imaginada. Buenos Aires: Paidos, 1999.

GIN, Pascal. Penser une culture de la mobilité. In: GIN, Pascal; MOSER, Walter (org.). Mobilités culturelles/Cultural mobilities. Ottawa: Presses de l'Université d'Ottawa, 2011. p. 329-347.

IMBERT, Patrick. Comparer le Canada et les Amériques des racines aux réseaux transculturels. Laval: Les Presses de l’Université de Laval, 2014.
IMBERT, Patrick. Trajectoires culturelles transaméricaines. Ottawa: Les Presses de l'Université d'Ottawa, 2004.

MAALOUF, Amin. Les Identités meurtrières. Paris: Éditions Grasset, 1998.

MELLO, Ana Maria Lisboa. Memórias e traços identitários em Nur na escuridão. Organon, Porto Alegre, v. 29, n. 57, p. 171-183, jul.-dez. 2014.

MIGUEL, Salim. Nur na escuridão. 4. ed. Rio de Janeiro: Topbooks, 2004.

OUELLET, Pierre. L'esprit migrateur. Essai sur le non-sens commun. Montreal: VLB Éditeur, 2005.

OUELLET, Pierre. Entretien avec Pierre Ouellet. Entrevista concedida a Ana Maria Lisboa de Mello, Marie-Hélène Paret Passos, Zilá Bernd. Letras de Hoje, Porto Alegre, v. 50, n. 2, p. 229-240, abr.-jun. 2015.

PATERSON, Janete. O sujeito em movimento: pós-moderno, migrante e transnacional The subject in motion: postmodern, migrant and transnational, Letras de Hoje, Porto Alegre, v. 50, n. 2, p. 179-184, abr.-jun. 2015.

RASSIER, Luciana Wrege. Immigration et enjeux identitaires dans Nur na escuridão. In: GODET, Rita Olivieri (org.). Écriture et identités dans la nouvelle fiction romanesque. Rennes: Presses Universitaires de Rennes, 2010. p. 191-208.

RASSIER, Luciana Wrege. Salim Miguel - dossiê temático (org.) Litteris, n. 8, set. 2011a.

RASSIER, Luciana Wrege. Identidade e imigração em Nur na escuridão, de Salim Miguel. Litteris, Rio de Janeiro, n. 8, set. $2011 \mathrm{~b}$.

SAINT-JACQUES,Sylvie. Entrevue avec Abla Farhoud Toutes celles que j'étais: la mémoire des illusions. Lapresse, 2015. Disponível em: <http://www.lapresse.ca/arts/livres/ entrevues/201506/05/01-4875561-abla-farhoudtoutes-cellesque-jetais-la-memoire-des-illusions.php $>$. Último acesso em 07 jun. 2015.

SCHIMIDT, Rita Terezinha. Pensando a literatura comparada como campo de singularidade e inovação. In: BITTENCOURT, Rita Lenira e SCHMIDT, Rita Terezinha (org.). Fazeres indisciplinados - estudos de literatura comparada. Porto Alegre: Editora da UFRGS, 2013. p. 297-308.

Recebido: 25 de abril de 2015

Aprovado: 15 de julho de 2015

Contato: luciana.rassier2010@gmail.com 